\title{
Tissue Responses and Solution Movement After Stem Wounding in Six Cycas Species
}

\author{
Jack B. Fisher \\ Fairchild Tropical Botanic Garden, 11935 Old Cutler Road, Coral Gables, \\ FL 33156
}

\section{Anders Lindström \\ Nong Nooch Tropical Botanic Garden and Resort, Chonburi 20260, Thailand}

\author{
Thomas E. Marler ${ }^{1}$ \\ College of Natural and Applied Sciences, UOG Station, University of Guam, \\ Mangilao, Guam 96923
}

Additional index words. cycads, Cycas edentata, Cycas elongata, Cycas hainanensis, Cycas macrocarpa, Cycas pectinata, Cycas revoluta, wound callus, wound periderm, water pathway

\begin{abstract}
We made drill holes in the stems of six Cycas species and used a standard microtechnique and microscopy methods to determine the structural responses of the soft-wooded, parenchymatous (manoxylic) stems after 2 and 12 months of recovery. We also injected an aqueous stain to one plant per species to determine the transverse hydraulic pathways among the discrete tissue categories. Expanding secondary tissue decay and insect larva infestations were evident in some wounds after 2 months. Wounds that lacked the secondary complications had recovered as a result of wound periderm after $\mathbf{2}$ months. Large areas of secondary rotting after $\mathbf{2}$ months were bounded by wound periderm after 12 months. The wound periderm formed a thick, leathery phellem (cork) that was continuous across cortex, vascular, and pith tissues. The six species represent a range in ease of horticultural management, yet the form of recovery from the wounds was similar for all species. Mucilage exudation from cut surfaces was copious, and species differences in volume of mucilage were also not related to extent or form of recovery from the wounds. Stain injected into the hole moved longitudinally and laterally within a vascular cylinder to adjacent vascular cylinders and to the cortex by way of persistent leaf traces. Results indicate a transverse hydraulic connection among the concentric vascular cylinders and leaf traces that extend into the cortex. Moreover, the succulent nature of this manoxylic stem is highly susceptible to secondary infection whenever the protective bark is removed or the internal tissues are injured. Therefore, use of prophylactic treatments to minimize the risk of secondary complications is warranted whenever pruning or amputation of adventitious shoots for propagation remove the protective bark from the succulent cortex tissue.
\end{abstract}

Contemporary cycads are derived from an ancient lineage of seed-bearing plants. All taxa are of considerable value to collectors because of their antiquity and unique features, and several species are represented in the nursery, landscape, and floriculture industries. The columnar stem of arborescent species lacks thin twigs found in other gymnosperms and is therefore classified as a pachycaulous tree (Stevenson, 1980). Cycads are often grouped with palms that are also pachycaulous (Norstog and Nicholls, 1997) because many horticulturists do not distin-

\footnotetext{
Received for publication 24 Feb. 2009. Accepted for publication 31 Mar. 2009.

Financial support was provided by the J. J. Mauget Company and the Western Pacific Tropical Research Center, Univ. of Guam.

We thank Mr. Kampon Tanshacha for encouragement and availability of plant material.

${ }^{1}$ To whom reprint requests should be addressed; e-mail tmarler@uguam.uog.edu.
}

guish the two very different groups of seed plants. The horticulture industry has contributed to the confusion by perpetuating the common name "sago palm" for Cycas revoluta Thunb. and "cardboard palm" for Zamia furfuracae L. f. These two species are represented in the horticulture industries more than any of the other roughly 300 living cycad species.

Palm stems are comprised of hard fibrous trunks with multiple scattered vascular bundles (Tomlinson, 1990). In contrast, cycad "wood" is a soft, highly parenchymatous xylem tissue with little lignified tissue, termed manoxylic (Greguss, 1968; Sporne, 1965). This succulent stem structure is unlike the more familiar dense and lignified xylem in woody stems of other gymnosperms (e.g., conifers, Gnetum, and Ginkgo). Cycad stems are also unusual in having concentric cylinders of vascular tissue (Fig. 1A) that are produced by multiple vascular cambia with each new additional cylinder differentiating at the base of the stem between the cortex and the peripheral youngest existing cylinder (Bork, 1990; Chamberlain, 1935; Terrazas, 1991). A persistent parenchymatous cortex is present in old, thickened stems and is not replaced by phloem or periderm like in other gymnosperms. Active cambial activity occurs within every vascular cylinder regardless of plant or vascular cylinder age, and parenchymatous rays connect the cortex and pith tissue (Terrazas, 1991).

More than half of the known cycad taxa are threatened or endangered (Donaldson, 2003). For Cycas species, the recent worldwide invasion of the cycad aulacaspis scale (Aulacaspis yasumatsui Takagi) is among the greatest of threats (IUCN Cycad Specialist Group, 2006). It has thrust natural populations of many species into a vulnerable position and devastated the international horticultural trade built on Cycas revoluta. Methods of managing the scale population on individual specimens are diverse, but management protocols that are appropriate and efficacious for large populations have evaded identification. Trunk injection of pesticides has been evaluated for widespread use on species of palm (e.g., Muthuraman, 1984), broad-leaved angiosperm (e.g., Harrell, 2006), and woody conifer (e.g., Doccola et al., 2003). Because of these successes, we recently evaluated the use of high-pressure injection of insecticide in stems of Cycas revoluta and five other Cycas species. Unfortunately, our results indicated that stem damage to the pachycaulous, manoxylic stem of this plant group was too great to advocate use of this pest management treatment on members of the genus.

Radial (Stevenson, 1980; Terrazas, 1991), developmental (Bork, 1990), allometric (Niklas et al., 2006; Niklas and Marler, 2008), and reaction (Fisher and Marler, 2006) growth characteristics have been described for the Cycas stem. However, little is known about the structural responses of this unique stem to an open wound. This void in information limits the definition of an appropriate means of treating pruned surfaces, cavities, or any other occurrence that causes the live cortex tissue to lose the protection of periderm and persistent leaf bases. Furthermore, the extent of transverse vascular connections among the various discrete tissues within this unique stem design has not been studied, which limits our understanding of Cycas physiology. Therefore, we exploited the rare opportunity to observe the internal stem structure of the plants that were sacrificed in the injection evaluation to describe the threedimensional movement of safranin stain and the anatomical responses to the wound that resulted from the injection hole. We observed wound dynamics over a 12-month recovery period and were most interested in timing of the induced responses and differences among the species.

\section{Materials and Methods}

The total number of plants examined for the following species are given in brackets: 

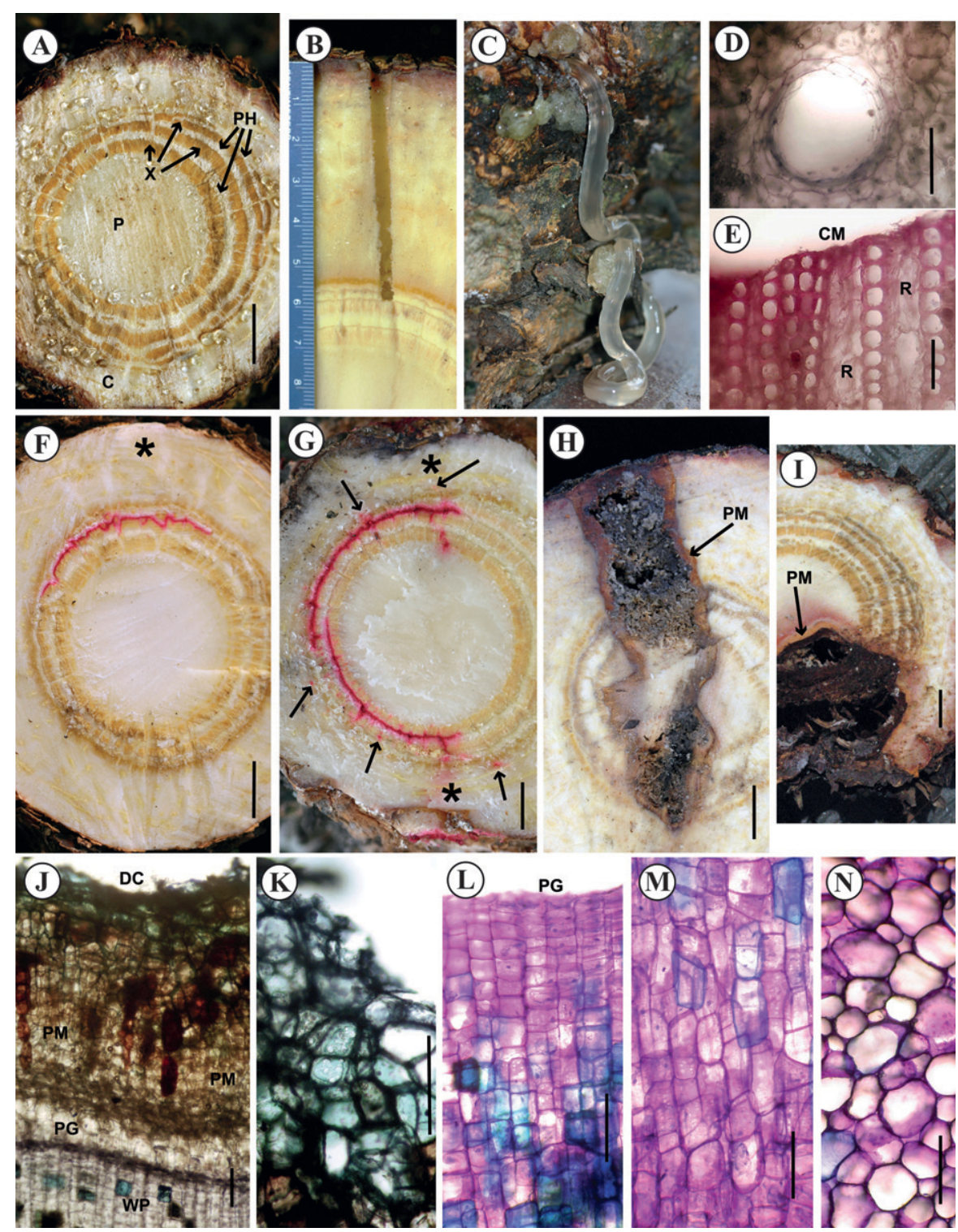

Fig. 1. (A-N) Stem sections of Cycas species. $C=$ cortex; $C M=$ vascular cambium; $D C=$ dead cells; $P=$ pith; $\mathrm{PG}=$ phellogen; $\mathrm{PH}=$ phloem $; \mathrm{PM}=$ phellem (cork); $\mathrm{R}=$ xylem ray; Star = position of safranin injection hole; $\mathrm{WP}=$ wound parenchyma; $X=x y l e m$. Scale bar $=2 \mathrm{~cm}$ in $\mathbf{A}$ and $\mathbf{F}-\mathbf{I} ;=200 \mu \mathrm{m}$ in $\mathbf{D}$ and $\mathbf{J}-\mathbf{N} ;=100 \mu \mathrm{m}$ in $\mathbf{E}$; ruler divisions in millimeters in C. (A) C. edentata surface of trunk $24 \mathrm{~h}$ after cutting with drops of mucilage; three to four rings of vascular tissue present at this level of stem. (B) Cut stem of $C$. pectinata immediately after hole was drilled; hole pierces the outermost of three vascular rings. (C) Mucilage tube exuding from hole in C. edentata $24 \mathrm{~h}$ after drilling. (D) Mucilage duct in transverse section of cortex of C. revoluta. (E) Xylem of C. elongata transverse section cut $25 \mathrm{~h}$ after safranin injection, mature xylem separated at vascular cambium during processing; youngest tracheids are most densely stained. (F) Distribution of safranin $24 \mathrm{~h}$ after single injection into stem of C. elongata; cut $4 \mathrm{~cm}$ above the injection hole. (G) Distribution of safranin $24 \mathrm{~h}$ after two injections into stem of C. edentata; cut $2 \mathrm{~cm}$ below injection holes; arrows indicate old leaf traces with safranin. (H) Injury at $2 \mathrm{~cm}$ below hole in C. pectinata; 2 months after injection. (I) Injury at $2 \mathrm{~cm}$ below hole in C. endentata; 12 months after injection. (J) Transverse section of wound periderm in C. pectinata cut 2 months after injection; showing tissue from surface dead cells to outer edge of wound parenchyma region. (K-N) Transverse section of wound periderm in C. pectinata cut 12 months after injection; series of views from surface phellem or cork $(\mathbf{K})$ to new wound parenchyma interior to the phellogen (L) to the mature wound parenchyma $(\mathbf{M})$ to the deeper unmodified cortex parenchyma $(\mathbf{N})$.

Cycas edentata de Laub. (nine), Cycas elongata (Leandri) D. Yue Wang (three), Cycas hainanensis C.J. Chen (three), Cycas macrocarpa Griff. (two), Cycas pectinata Griff. (18), and Cycas revoluta Thunb. (three) were selected from the landscape production stock at Nong Nooch Botanical Garden and Resort, Chonburi, Thailand, in Apr. 2007. The healthy plants had well-developed stems with three or more vascular cylinders at the base (Fig. 1A) and were cultivated in pots (height $40 \mathrm{~cm} \times$ diameter $35 \mathrm{~cm}$ ) in a shadecloth production area. Standard fertilization and irrigation were applied before and after treatment.

Two treatment holes per trunk were used for stem injection methods. In every case, a 6- $\mathrm{mm}$ drill bit was used to create a hole through the periderm and cortex until the outermost vascular cylinder was reached (Fig. 1B). Drill bit and stem surfaces were not sterilized. One plant of each species was injected with $\approx 7$ $\mathrm{mL}$ of a $1 \%$ aqueous solution of safranin stain in each hole with an initial 200 psi pressure applied for $60 \mathrm{~s}$ or less as recommended by the manufacturer (Sidewinder Pty Ltd., Noosaville, Australia). Other plants received various injection treatments of $7 \mathrm{~mL}$ each for long-term pesticide evaluation. The injector was removed from the hole in accordance with the manufacturer's instructions. The threaded injector tip and the plastic screw plug (from the manufacturer) caused some crushing of the edges of the drilled holes so that the injury did not have clean cut surfaces.

We observed the internal stem structure of the plants on three occasions. The plants receiving the safranin treatment were sampled $24 \mathrm{~h}$ after administering the stain. Our purpose was to determine the threedimensional movement of the injected solution. Half of the remaining plants were sampled after 2 months of recovery from the drilled hole, and the other half were sampled after 12 months of recovery. The stems were dissected initially with a hand saw to make the primary cuts near the injection holes. Thereafter, we used sharp blades to make the more refined cuts so that tissue boundaries were clear. Images of freshly cut surfaces were captured with a digital camera.

For all three sampling periods, appropriate tissue samples were preserved in formalin-alcohol-acetic acid (FAA) and stored in $70 \%$ ethanol. Unembedded tissue was sectioned with either a sliding microtome or razor at various thicknesses. Sections were stained with toluidine blue $\mathrm{O}$ (for general histology), phloroglucinol: $\mathrm{HCl}$ (for lignified cell walls), $\mathrm{I}_{2} \mathrm{KI}$ (for starch), and Sudan IV (for cutinized and suberized cell walls) (Ruzin, 1999). Anatomical images were captured with a digital camera on a compound microscope.

\section{Results}

Initial observations. Mucilage canals were present throughout the cortex but were concentrated in the peripheral region of the pith (Fig. 1A). Within vascular cylinders, canals as seen by accumulated exudation on surfaces of cuts were restricted to the parenchymatous regions between vascular rings and in the outer phloem region. Mucilage was visible seconds after cutting in some species and exuded from the drilled holes or surrounding surface cuts after minutes or hours. The greatest volume of mucilage exudation was observed in $C$. edentata. In this species, mucilage flowed copiously from all drilled holes in replications (Figs. 1A and 1C). Mucilage canals were conspicuous in all six species and exhibited similar phenotype regardless of species (Fig. 1D).

Injected safranin moved acropetally and basipetally from the injection site and 
circumferentially through tracheids of the xylem (Fig. 1E). Safranin binds permanently to cell walls and its solution has limited staining distance. However, we could not clearly distinguish dye movement caused by the initial high-pressure injection from later translocation through xylem sap flow. Vascular leaf traces weave irregularly through the cortex (darker dots in cortex of Figs. 1B and $1 \mathrm{~F}-\mathrm{I}$ ), and many of these leaf traces exhibited movement of the safranin into the cortex (Fig. 1G). The circumferential movement was up to one-third the circumference of the vascular ring. The youngest tracheids in a xylem cylinder were the most efficient in transport under our conditions as evidenced in the greater staining of the youngest tracheid several centimeters above or below the hole (Fig. 1E)

Two-month observations. Secondary expansion of necrotic tissue and rot around the holes and especially in the vascular tissue above and below the holes was apparent after 2 months (Fig. 1H). The extent of tissue damage was greater in holes treated with insecticide than in holes that remained untreated, but the wound response was similar to both causes of tissue necrosis. Discoloration from polyphenolic compounds formed around all holes or adjacent to peripheral regions of tissue necrosis. Parenchyma cells expanded and files of new cells developed perpendicular to the injury, thus producing a wound periderm (Fig. 1H). In every case, the rotting tissue that was excluded by the wound periderm was wet. Some necrotic areas had fungal growth (fruiting bodies seen), putrefaction, and/or unidentified insect larvae. Putrefaction was the result of the high starch content in parenchyma. Holes that lacked secondary rotting of cortex tissue were healed by the formation of wound periderm and cell proliferation by 2 months.

Twelve-month observations. Further expansion of the rotting tissue did not occur after the 2-month observations. The anatomical structure of the wound response was basically the same in all six species. A thick wound periderm effectively concealed the damaged tissue such that the wet, necrotic regions had become dry, hollow spaces by 12 months (Fig. 1I). Natural periderm was generally less than $1 \mathrm{~mm}$ thick for all species except $C$. pectinata, which had periderm up to $1.5 \mathrm{~mm}$ thick (Fig. 1B). The wound periderm was considerably thicker, exhibiting a contiguous sheet of phellem 3 to $4 \mathrm{~mm}$ thick in some samples. In contrast to the natural periderm, wound periderm thickness for C. pectinata did not differ from that of the other species. The necrotic hollow spaces were lined with dry, black tissue remnants. A hard light-colored crust (Fig. 1I) composed of air-filled, thin-walled cork cells with suberolignified thin cell walls (determined from Sudan IV staining) was the outermost layer of the wound periderm (Figs. $1 \mathrm{~J}$ and $1 \mathrm{~K}$ ). The crust broke free easily at the phellogen, which ended several millimeters of phelloderm comprised of parenchyma cell files perpendicular to the necrotic surface (Figs.
$1 \mathrm{~L}$ and $1 \mathrm{M})$. This region of proliferation and the adjacent parenchyma region of unmodified, larger and rounder cells were darkened as a result of scattered tannin cells and pigmentation of cell walls. The rounder, undivided parenchyma cells were filled with starch (determined with IKI staining) like typical cortex or pith parenchyma cells in undamaged plants (Fig. 1N).

The secondary necrosis of many replications expanded to include cortex, vascular cylinders, and pith tissue. In these cases, the parenchyma of xylem rays and all the phloem were involved in cell proliferation within the vascular cylinder region (Figs. $1 \mathrm{H}$ and 1I). The result was synthesis of a contiguous wound periderm that appeared homogeneous in structure across all tissue zones. Wound periderm formation was similar regardless of wound size or the volume of the cavities created by a secondary response to the drilled hole and pesticide injection. Parenchyma cells next to leaf traces occasionally formed a series of thick-walled, lignified cells with tracheidlike bordered pits, but these were scattered in the stem and without clear pattern. Leaf traces in nonproliferated regions next to damaged areas had normal unchanged anatomy with healthy xylem and phloem cells.

\section{Discussion}

We selected $C$. revoluta because it is the most popular cycad species for horticultural use and because it is considered one of the most hardy. We selected the other five species to provide a range of tolerance to horticultural operations based on our past experience (A. Lindström, unpublished data). Cycas macrocarpa is the most difficult species to care for in horticultural settings. Transplanting or damage to the trunk frequently leads to plant death. The other four species rank between these two extremes. These six Cycas species exhibited similar behavior in terms of wound periderm formation. The living parenchyma cells of cortex, vascular rings, and pith that are adjacent to the initial hole or later necrotic tissues undergo mitoses and produce files of cells perpendicular to the surface of the hole or damaged areas. This response is observed with other instances of mechanical injury in plants (Fink, 1999). This proliferation then develops a localized phellogen that forms a typical phellem (cork) layer. All species formed equivalent wound periderm. Therefore, the manner in which wound periderm is initiated and synthesized in the Cycas stem does not appear to account for the differences in hardiness, the ability to recover from stem injuries, transplanting, or repotting among the species.

Wound periderm formation was highly effective at excluding the damaged area and proliferating substantial phelloderm to adjoin undamaged parenchyma tissue regardless of the ultimate volume of secondary necrosis. This anatomical response to injury and infection is analogous to the compartmentalization of infection by a "barrier zone" that develops from the living cells in the wood of pycnoxylic conifers and dicotyledonous trees (Shigo, 1984). Therefore, pruning or removing adventitious shoots for propagation from Cycas stems (or occurrence of any form of damage that exposes cortex) should be followed up with prophylactic treatments to avert secondary invasion of pathogens or ovipositioning by arthropods to give the phellogen time to differentiate immediately adjacent to the original wound. Unquestionably, the succulent and starchy nature of this manoxylic stem is highly susceptible to secondary complications whenever the protective periderm is removed or damaged. Incipient phellogen may succumb to expanding necrosis if appropriate cultural practices are not implemented to minimize the secondary complications. Filling cavities in Cycas stems with insulating foam sealants has been advocated as one method of protecting the exposed surfaces within the cavity (Holzman, 2005).

A copious amount of parenchyma forms in the vascular rays and is interspersed throughout the vascular cylinder region of the Cycas stems. This natural abundance of parenchyma may have enabled the remarkably homogeneous thick, leathery sheet of phellem that extended from cortex to pith in the wound periderm.

Although the role of cycad mucilage has not been identified, it may serve to seal and protect the surface of damaged tissue (Norstog and Nicholls, 1997). In our study, all six species exhibited mucilage exudation from the cut surfaces. However, there were differences in volume expressed with Cycas edentata exhibiting the greatest volume. This disparity in mucilage expression among the species did not appear to correlate with recovery from the drilled holes. These observations do not support our initial assumption that mucilage protects damaged surfaces from the devastating secondary necrosis.

The six species of Cycas exhibited similar behavior in terms of three-dimensional safranin movement among the tissue categories. At positions 20 to $40 \mathrm{~mm}$ above or below the injection location, safranin spread circumferentially in the vascular cylinder that initially received the dye and then moved to adjacent vascular cylinders and cortex tissue through leaf traces. The manoxylic construction of a Cycas stem presents a challenge for maintaining biomechanical integrity as the individual grows tall. Norstog and Nicholls (1997) consider the unusual leaf trace arrangement as instrumental in creating a supportive skeleton throughout the cortex. The typical leaf trace follows a circuitous path up to $140^{\circ}$ circumferentially around the cortex from the inner vascular cylinder to the leaf base it serves (Stevenson, 1980). Although histological studies have discussed the convoluted path of leaf traces and the relationship among the vascular cylinders, our methods provide the first validation of the efficient transverse translocation of a solution throughout these tissues using an experimental approach. Our observations indicate a distribution system of anastomosis 
that connects the vascular cylinders with the periphery of the cortex by the network of leaf traces passing through all vascular rings. Cambial activity occurs simultaneously among all vascular cylinders (Terrazas, 1991) to form new tracheids in each cylinder and possibly in xylem strands that connect the concentric vascular cylinders.

Based on our study, the vascular tissues of Cycas stems are highly susceptible to direct damage by physical pressure. Furthermore, exposed cortex tissue after any form of injury to a Cycas stem is vulnerable to secondary developmental complications. Our work indicates the use of prophylactic treatments to reduce access by arthropods and pathogens is warranted to minimize the risk of secondary complications whenever a natural event or horticultural practice removes the protective bark from the succulent cortex tissue.

\section{Literature Cited}

Bork, J. 1990. Developmental cycles in shoot growth of male Cycas circinalis. Amer. J. Bot. 77:981-985.

Chamberlain, C.J. 1935. Gymnosperms: Structure and evolution. University of Chicago Press, Chicago, IL [1966 reprint. Dover Publications, New York, NY].
Doccola, J.J., P.M. Wild, I. Ramasamy, P. Castillo, and C. Taylor. 2003. Efficacy of Arborjet Viper microinjections in the management of hemlock wooly adelgid. J. Arbor. 29:327330 .

Donaldson, J.S. 2003. Introduction. In: Donaldson J.S. (ed.). Cycads, status survey and conservation action plan. IUCN, Gland, Switzerland, and Cambridge, UK.

Fink, S. 1999. Pathological and regenerative plant anatomy. Handbuch der Pflanzenanatomie Band 14, Teil6. Gebrüder Borntraeger, Berlin, Germany.

Fisher, J.B. and T.E. Marler. 2006. Eccentric growth but no compression wood in horizontal stem of Cycas micronesica (Cycadales). Intl. Assoc. Wood Anat. J. 27:377-382.

Greguss, P. 1968. Xylotomy of the living cycads. Akadémiai Kiadó, Budapest, Hungary.

Harrell, M. 2006. Imidacloprid concentrations in green ash (Fraxinus pennsylanica) following treatments with two trunk-injection methods. Arboricul. Urban For. 32:126-129.

Holzman, G. 2005. Foam filler for cycad trunk wounds. Cycad Newsl. 28:16.

IUCN Cycad Specialist Group. 2006. Report and recommendations on cycad aulacaspis scale, Aulacaspis yasumatsui Takagi (Hemiptera: Diaspididae). IUCN/SSC Cycad Specialist Group-Subgroup on Invasive Pests. 1 May 2009. $<$ http://www.cycadsg.org/publications/CAS/ Cycad-Aulacaspis-Scale-Pest-Alert.pdf $>$.
Muthuraman, M. 1984. Trunk injection of undiluted insecticides - A method to control coconut red palm weevil, Rhynchophorus ferrugineus Fab. Indian Coconut J. 15:12-14.

Niklas, K.J., E.D. Cobb, and T. Marler. 2006. A comparison between the record height-to-stem diameter allometries of pachycaulis and leptocaulis species. Ann. Bot. (Lond.) 97:79-83.

Niklas, K.J. and T.E. Marler. 2008. Sex and population differences in the allometry of an endangered cycad species, Cycas micronesica (Cycadales). Intl. J. Plant Sci. 169:659-665.

Norstog, K.J. and T.J. Nicholls. 1997. The biology of the cycads. Cornell University Press, Ithaca, NY.

Ruzin, S.E. 1999. Plant microtechnique and microscopy. Oxford University Press, New York, NY.

Shigo, A.L. 1984. Compartmentalization: A conceptual framework for understanding how trees grow and defend themselves. Annu. Rev. Phytopathol. 22:189-214.

Sporne, K.R. 1965. The morphology of gymnosperms. Hutchinson University Library, London, UK.

Stevenson, D.W. 1980. Radial growth in the Cycadales. Amer. J. Bot. 67:465-475.

Terrazas, T. 1991. Origin and activity of successive cambia in Cycas (Cycadales). Amer. J. Bot. 78: 1335-1344.

Tomlinson, P.B. 1990. The structural biology of palms. Clarendon Press, Oxford, UK. 